\title{
INVESTIGATION OF THE COOLANT FLUID FLOW DISTRIBUTION IN THE GRINDING GAP
}

\author{
C. Baumgart ${ }^{1 *}$, K. Wegener ${ }^{1}$ \\ ${ }^{1}$ ETH Zürich, Institute of Machine Tools and Manufacturing, Zurich, Switzerland \\ *Corresponding author; e-mail: baumgart@iwf.mavt.ethz.ch
}

\begin{abstract}
In grinding the use of coolants is inevitable to achieve high precision surface properties under the need of high process performance and under reasonable material removal rates. In conventional grinding typically a significant share of the total production energy refers to the delivery and conditioning of the coolants due to the use of flood cooling, which contributes a significant portion to the production costs. However despite trends of minimal quantity lubrication and even dry grinding, the demand of metal working fluids is increasing worldwide. In order to reduce and optimize the use of coolants, profound knowledge about the fluid delivery into the grinding gap is important. Usually studies show the effect of coolants on the grinding process by the effect on the workpiece. They allow general conclusions about the share and distribution of the useful coolant flow, which is considered as the coolant flow into the grinding gap. On the other hand in-process methods can be used to assess the coolant flow. In a newly proposed experimental set-up the distribution by different nozzle designs and volume flows, respectively flow speeds, are studied for a cylindrical grinding process and can directly be visualized. Effects of the grinding wheel induced air-flow are fully considered. The main evaluation is done along the workpiece axis. It is shown that the distribution of the coolant flow inside the grinding gap is typically not entirely uniformly, also when nozzles with a consistent coolant supply are employed. Coolant distribution depends on the nozzle outlet cross-section, while different nozzle design can lead to even grinding results. It is shown, that the amount of cooling flow is not the main parameter. The influence region of single jet nozzles is typically much wider that their cross-section, which allows to use them in grinding. The results combined with a heuristic approach allow the optimization of coolant jet nozzles for grinding processes.
\end{abstract}

\section{Keywords:}

Grinding; Coolant supply; Coolant nozzles; Grinding fluid flows; Grinding gap; Metal working fluids

\section{INTRODUCTION}

"It is dark in front of the grinding grain" is an expression coined by Tönshoff et al. [Tönshoff 1998] referring to the unknown of the grain-surface interaction including the coolant supply. The proposed approach in this work aims to shed light into the grinding gap to improve the knowledge about the coolant supply mechanisms in the grinding process and the distribution of coolants in the grinding gap. Grinding is an important finishing process for typically hard and very difficult to machine materials, with almost no limit to grind as defined by Fritz [Fritz 2018]. Aurich et al. [Aurich 2014] states that the negative rake angles in a large number of undefined cutting edges distinguish the grinding process from other cutting processes giving a high stability and resistance of the tool. On the other hand this material cutting process is characterized by a huge amount of roughing and ploughing on the workpiece surface due to the kinematics of the energy intensive process. Malkin and Anderson [Malkin 1974] stated that about 55 percent of the chip formation energy plus almost all ploughing and sliding energy are lead into the workpiece as heat. This energy portion depends very much on the process but typically long contact times between tool and workpiece affirm the trend [Tönshoff1997, Karpuschewski 1995]. The high heat generation needs to be extracted by the use of metal working fluids (MWF). Various supply methods have been developed and optimised to improve the MWF supply and MWF efficiency. Marinescu et al. [Marinescu 2013] name cooling, lubrication and transport of chips as the main functions of MWFs in grinding. Therefore changes in the coolant system might cause a multivariable impact on the process. Jackson et al. [Jackson 2005] expected three benefits along the optimization of the coolant supply, with reduced cost for the manufacturer, less environmental impact and even possible process improvements.

High MWF related productions costs of up to $17 \%$ are shown by Klocke and Bücker [Klocke 1996]. Many publications in the last decades examine minimum quantity lubrication (MQL) or dry grinding as possible strategies to replace flood cooling and reduce costs. MQL is an intermediate loss supply method, which was tested successfully by da Silva et al. [da Silva 2013] in comparison with conventional cooling by means of residual stresses, micro-hardness or roughness. Sreejith et al. [Sreejith 2000] emphasize on the complexity of dry machining in general asking for measures to compensate the absence of coolants. Azarhoushang et al. [Azarhoushang 2017] show an approach by using structured wheels to reduce forces 
and workpiece temperatures allowing dry grinding without thermal damage. Dixit et al. [Dixit 2011] show advantages of dry machining as less environmental impact and better, healthier working conditions. On the other hand disadvantages exist in process performance, thermal workpiece damage and dimensional inaccuracy as emphasised by Tawakoli and Azarhoushang [Tawakoli 2008]. Nevertheless Klocke and Bücker [Klocke 1996] were predicting the situation correct in 1996, with their statement that MQL or dry grinding remain niche applications for the near future.

Jackson et al. [Jackson 2005] stated that the often referred term 'useful flow' in grinding is not defined precisely, but often related to the amount of fluid passing through the grinding gap. Several models exist to estimate the coolant flow necessary to cool the grinding process adequate to avoid thermal damage. These models are often based on geometrical conditions as the theoretical fluid layer thickness shown by Marinescu et al. [Marinescu 2013] or wheel topography as presented by Cui [Cui 1995]. As the air flow around the grinding wheel does influence the coolant supply, which is proven by many studies [Gviniashvili 2004, Wang 2014], it has to be taken into account also.

Important parameters of the coolant jet are given by Morgan et al. and Heinzel et al. [Morgan 2008, Heinzel 2015] with the jet velocity respectively ratio of flow speed to cutting speed and orientation. Also the outlet area is named as an important area, but typically no considerations about the axial distribution are made, while the air flow of the grinding wheel is not homogeneous along the grinding wheel width. In order to evaluate the effect of the coolant supply various test rigs have been designed. Wittmann et al. [Wittmann 2004] made use of a set-up developed by Powell [Powell 1979] to characterise the amount of fluid passing though the grinding gap. The method is indirect, as the feed is stopped and the energy to keep the temperature of a heating plate within the grinding gap constant is measured and related to the flow through the grinding gap. No information about the distribution of the coolant or the progression of the fluid in the grinding gap can be given as the values are averaged over the width of the grinding wheel.

\section{EXPERIMENTAL SET-UP OF GRINDING GAP FLOW OBSERVATION}

In this work the flow of MWF within the grinding gap during the grinding process is investigated. Main interests are the filling and distribution of the fluid due to different supply conditions by various jet nozzles and flow rates. As stated in the introduction the airflow, induced by the rotating grinding wheel, has a high impact on the filling of the grinding gap with MWF and thus the efficiency of cooling. Therefore grinding speeds with actual grinding wheels (topography, porosity) have to be reproduced accordingly in the test set-up. Furthermore in order to achieve geometrical contact conditions with real grain intrusion and flow conditions as close as possible to real grinding, the experimental set-up is placed in a cylindrical grinding machine as shown in Fig. 1.

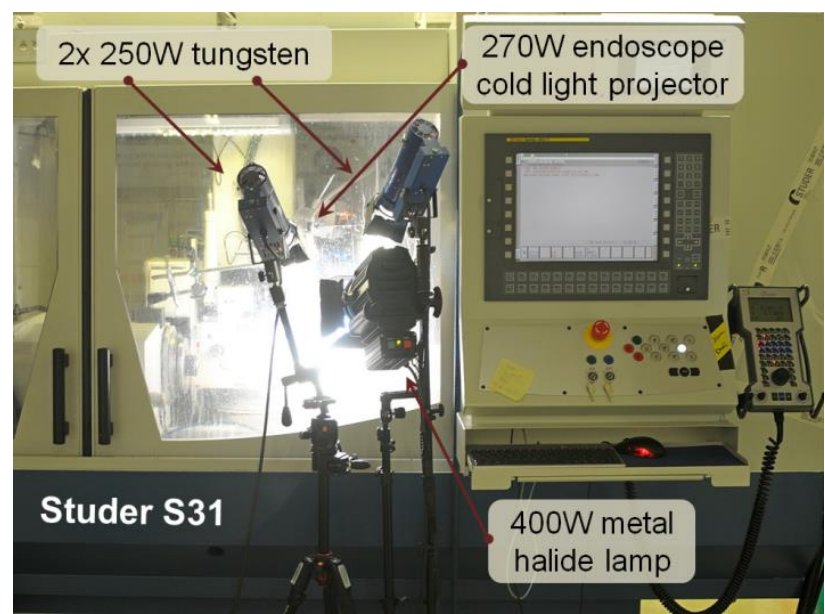

Fig. 1: Studer S31 machine Set-Up with illumination system.

\subsection{Grinding geometry and flow observation}

To allow the observation of the flow the rotating workpiece is replaced by a stationary and transparent Plexiglas tube, as shown in Fig. 2.

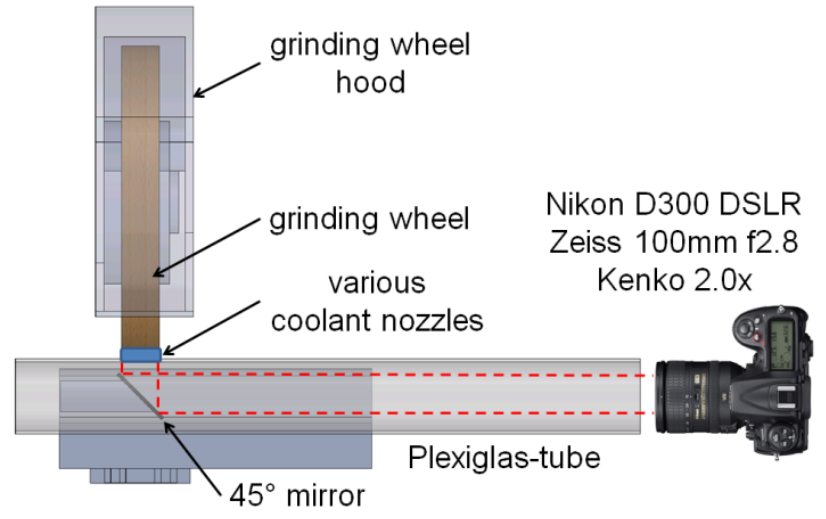

Fig. 2: Experimental set-up in grinding machine.

The Plexiglas-tube is fixed on the tailstock in the machine as it would be the workpiece. Inside the tube a mirror is placed in a $45^{\circ}$ angle to reflect the image from the grinding gap to the camera (light path illustrated by red dotted-lines). A Nikon D300 DSLR camera is chosen to provide a relatively high image resolution leading to higher number of pixels along the grinding gap. The camera is combined with a Zeiss $100 \mathrm{~mm}$ F2.0 macro lens (Makro-Planar T*2/100) on a Kenko 2.0x teleconverter, which allows a close image section and good detail over the distance between mirror and camera of approx. $800 \mathrm{~mm}$. The machine could be accessed from the side door using plastic covers to avoid coolant splashes on the camera system as the other side of the tube was sealed after aligning the mirror to the camera system.

In order to orient the axis of the tube to the one of the grinding wheel the grinding wheel is first positioned close to the Plexiglas tube. Then the tube can be manually adjusted to the grinding wheel before the tube holder is finally fixed on the tailstock.

During the experimental procedure the grinding wheel is moved away from the tube to start the rotation and then manually moved back close to the last position during fixation of the tube. Positioning errors as well as dilatation effects of the wheel are unknown, the contact point is judged by the camera image. The wheel is grinding into the tube to a certain grinding depth $a_{e}$, where the images are 
recorded according to different nozzles and flow rates. The cutting speed is set to $v_{c}=50 \mathrm{~m} / \mathrm{s}$ using a Winterthur $/ 3 \mathrm{M}$ grinding wheel with $D=500 \mathrm{~mm}$ diameter and $B=63 \mathrm{~mm}$ width (54A $120 \mathrm{H} 15$ VPMF604W). The Plexiglas tube is made of extruded acryl glass with a transmissivity of more than $90 \%$ including UV radiation.

While an actual grinding set-up can be used some simplifications are made. First, the Plexiglas tube (i.e. workpiece) is stationary. Typically the speed ratio is in the range of 60-120 (depending of process, materials etc.), which allows to neglect the rotational speed of the tube. On the other hand no feed is applied during the image recording. This procedure is similar to the test-rig of Powel [Powell 1979, Wittmann 2004]. As "long"-exposures are taken the resulting distribution refers to a steady state or averaged value of the coolant distribution.

\subsection{Illumination}

In order to achieve good illumination conditions several light sources are used. Inside the grinding machine a Storz $270 \mathrm{~W} 45 \mathrm{~V}$ endoscope cold light projector is positioned above the grinding gap as a spot light. Additionally from outside two $250 \mathrm{~W} 24 \mathrm{~V}$ tungsten spot lights and a $400 \mathrm{~W}$ daylight metal halide lamp are placed in front of the grinding machine as seen in Fig. 1.

\subsection{Coolant nozzles}

In the presented experiments three different types of jet nozzles are tested, namely:

- $\quad$ single round-jet nozzles (1.5mm and $3.0 \mathrm{~mm}$ diameter);

- single-flat nozzle (1.5mm opening and $63 \mathrm{~mm}$ width);

- 3x Loc-Line nozzles;

First and second nozzles are shown in Fig. 3. The whole width of $63 \mathrm{~mm}$ of the grinding wheel is aimed to be flooded homogeneously. The observation of the flow in the grinding gap shall help to understand the differences in the coolant flow distribution inside the grinding gap due to the supply by different coolant nozzles. The used coolant is four percent emulsion of Blaser Swisslube B-Cool 9665.
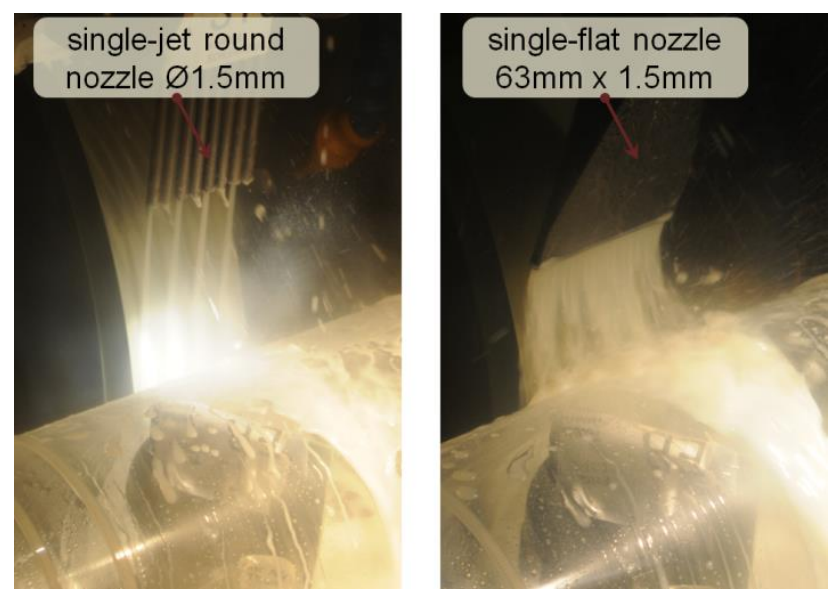

Fig. 3: Single round-jet nozzles (left) vs. single-flat nozzle (right).

\section{MEASURING AND MODELLING METHODS}

\subsection{Recording of images}

With the prepared set-up and the engaged grinding wheel the exposure time of the image acquisition is defined with $t_{s}=1 / 60 \mathrm{~s}$. This value is found as a balance between contrast of the coolant in the grinding gap and enough time to average the introduced coolant supply into the grinding gap. In preparation to the image processing, the images are rotated to horizontal alignment and cut to the grinding gap zone producing TIFF-files with a resolution of $2255 \times 450$ pixels (px) as presented in Fig. 4, which also shows the porosity of the grinding wheel. The slightly visible vertical lines origin from the scratches of the grinding process into the Plexiglas.

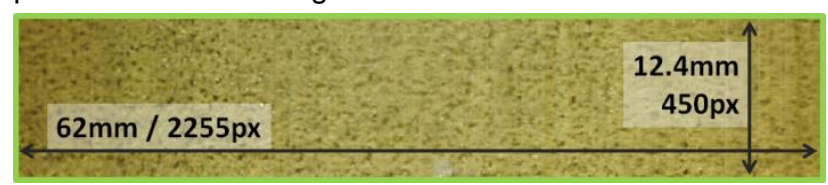

Fig. 4: Grinding wheel surface and resolution of images. The images consists of 2255 columns with 450 vertical values each

\subsection{Image processing}

The images are saved in Tiff-24-bit RGB format containing red, green and blue colours in three matrices. In a first step all images are imported into a MATLAB script to be converted into Tiff-8-bit greyscale images, while one is shown in Fig. 5.

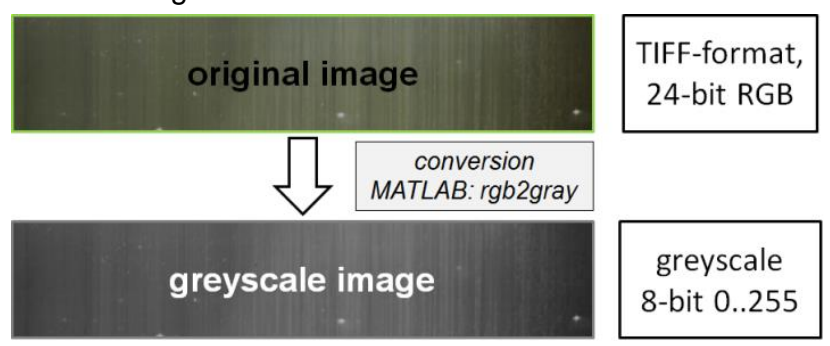

Fig. 5: Image processing, $1^{\text {st }}$ step: Greyscale conversion.

Two corrections are applied to the images. First the light distribution due to the illumination system is balanced. Three images without coolant are used to determine the light distribution along the grinding gap, which is shown in Fig. 6. A plot represents the curves for one exemplary image showing the greyscale intensities as mean values over the width of the grinding wheel. The mean is calculated over each $450 \mathrm{px}$ vertical values along the $2255 \mathrm{px}$ picture width as shown in Fig. 4. Blue represents the raw values showing a higher intensity of light in the centre of the grinding wheel width, which probably originates from an unequal light source, and black the corrected curve. The correction is calculated by first taking the average of three raw signals calculating the average light intensity Iraw_av in the grinding gap. The maximum of this curve is formed by the average of the about 550 highest values of this curve ( $\left.I_{\max }\right)$, which is done to gain a smoothing of the maximum value. The red correction curve $I_{\text {corr }}$ for the intensity results from:

$$
I_{\text {corr }}=\left[-\left(I_{\text {raw }}-I_{\text {max }}\right)\right] \cdot 0.75
$$

Savitzky-Golay filtering with a polynomial order plot with wide frame-length is used to smooth the curves. The factor 0.75 is used to weight the impact of the correction. 


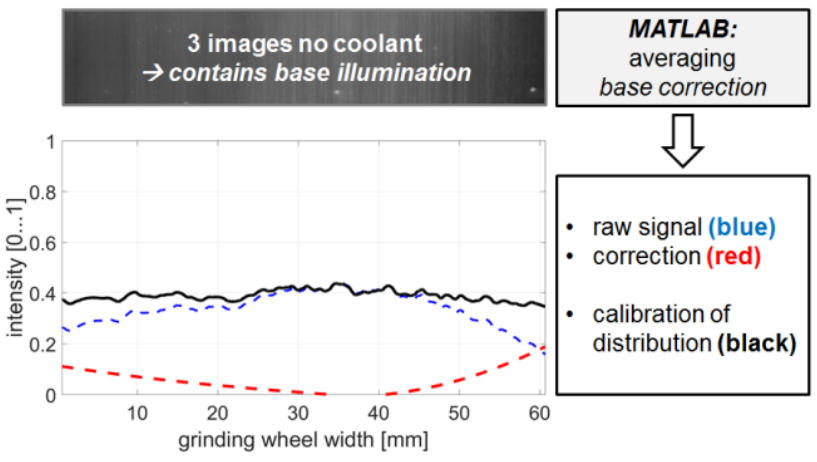

Fig. 6: Image processing $2^{\text {nd }}$ step: Illumination intensity correction.

Finally, in the $3^{\text {rd }}$ step the images with coolant are normalised for a better comparison. This is done by calculating a conversion factor for the images, which is formed by the image with the highest mean values. Subsequently all images are corrected by the value of the highest intensity of the image assuming the highest possible coolant distribution, which is shown in the blackcurve as the normalized intensity in Fig. 7.

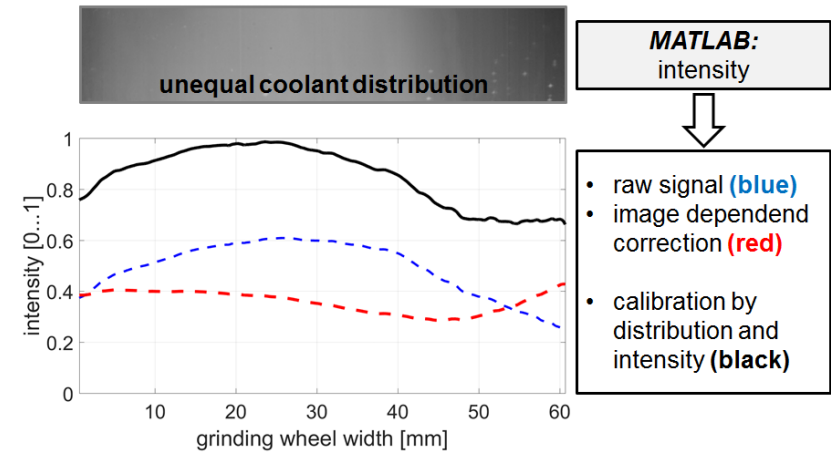

Fig. 7: Image processing $3^{\text {rd }}$ step: Intensity.

\section{GRINDING EXPERIMENTS AND RESIDUAL STRESS MEASUREMENT}

Analog to the observation of the MWF-flow in the grinding gap, grinding experiments are conducted to compare the findings with the impact of the fluid supply on the workpiece surface. Basically the same set-up is used, while the Plexiglas tube is replaced by cylindrical workpieces. These consist of hardened (62-64 HRC) cold work steel 1.2842 (90MnCrV8) in the dimension $\varnothing 60 \mathrm{~mm}$ and $60 \mathrm{~mm}$ width. As grinding parameters a roughing feed rate of $0.4 \mathrm{~mm} / \mathrm{min}$ is chosen, which correlates to a specific material removal rate of about $Q_{w}^{\prime}=1 \mathrm{~mm}^{3} /(\mathrm{mm} \mathrm{s})$, as used in fine grinding. Furthermore neither fine feed nor spark out is applied. Similar to the flow observation experiments, various different coolant flows are applied during the grinding process.

Residual stresses belong to the process footprint in the workpiece and are part of the subsurface changes, playing a major role in grinding. Intentionally compressive stresses are induced into the workpiece surface due to grinding with suitable grinding parameters. They result from thermal and mechanical loading, which depend on a multiplicity of parameters including the process parameters, the used tool and the dressing conditions. Last but not least MWFs do have a very high impact on the tribological system influencing the grain-workpiece contact as well as thermal balance in the grinding gap. The effect and efficiency of cooling and lubrication depends on the supply of the MWF into the grinding gap, which is influenced by the coolant nozzles.

In order to judge the coolant distribution along the workpiece axis parallel to the observed coolant distribution, non-destructive superficial residual stress measurements are performed. For that purpose X-ray diffraction method is applied with the Stresstech Xstress 3000 G3, as shown in Fig. 8. Based on known crystal-structure and characteristic wavelengths of the X-ray-tube, diffraction angles can be chosen to determine the tangential stress state of the workpiece surface (tensile or compressive stresses). The measurement depth is in the range of 1-10 $\mu \mathrm{m}$.

The measurements are conducted along the workpiece axis in a range covering the grinding wheel contact, from $2 \mathrm{~mm}$ to $58 \mathrm{~mm}$ of the workpiece width. The error of the residual stress measurements is generally specified in the range of $\pm 20 \mathrm{MPa}$.

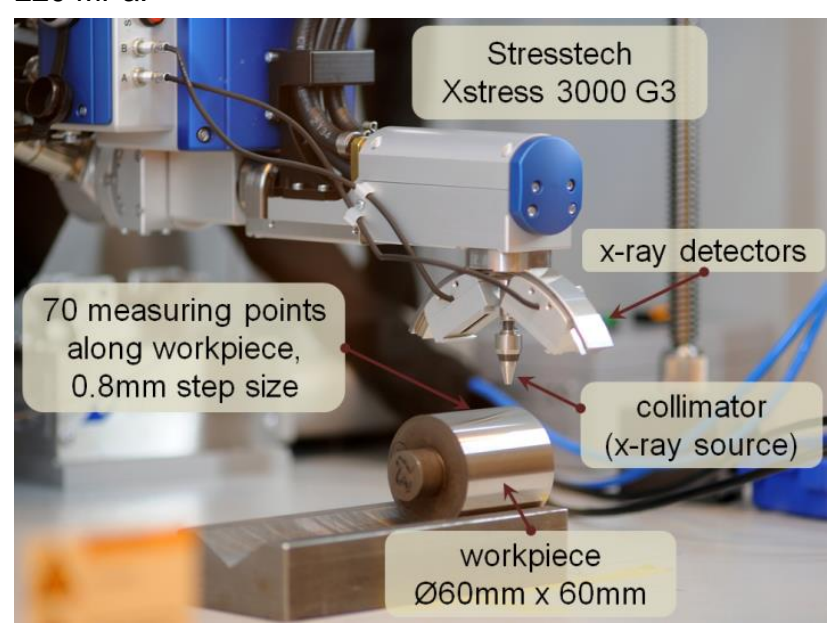

Fig. 8: Residual stress measurement with X-Ray diffraction method.

\section{RESULTS AND DISCUSSION}

\subsection{Tested nozzles and volume flows}

For the observation of the coolant flow various nozzles and volume flows are investigated. As for the single-jet round nozzles different compositions are used as indicated in Fig. 3 for four nozzles. One, four or 8 nozzles can be employed at the same time with adaptable volume flow. In Tab. 1 all used configurations are shown including total volume flow, standard deviation and average intensity. The standard deviation is here defined as a measure for the uniformity of the coolant distribution in the grinding gap while the average intensity is the mean value of the intensity along the whole grinding contact and therefore the mean filling with coolant. Maximum calculated fillings of about 80 percent are achieved.

The numbering schemata of the single round-jet nozzles includes the diameter ( 1 equals to $\varnothing 1.5 \mathrm{~mm}$, while 3 equals to $\varnothing 3.0 \mathrm{~mm}$ ) and the arrangement (place 1-8 means equally distributed nozzles with $7 \mathrm{~mm}$ axial distance each). It can be stated that typically a higher volume flow shows a better filling of the grinding gap by a higher intensity. A better uniformity is given by a lower standard deviation along the coolant distribution. 
Tab. 1: Compared nozzles and fluid volume flows. The standard deviation is a measure for the uniformity of the coolant distribution while the average intensity is the mean value of the intensity along the whole grinding contact.

\begin{tabular}{crcc} 
Nozzles & I/min & $\begin{array}{c}\text { std. } \\
\text { deviation }\end{array}$ & $\begin{array}{c}\text { avg. } \\
\text { intensity }\end{array}$ \\
\hline 00010000 & 3.0 & 6.2 & 0.65 \\
00030000 & 6.0 & 5.8 & 0.87 \\
10000000 & 3.0 & 5.0 & 0.49 \\
10101010 & 10.0 & 4.2 & 0.81 \\
11111111 & 6.0 & 4.7 & 0.74 \\
30000000 & 6.0 & 6.7 & 0.61 \\
30303030 & 6.0 & 4.8 & 0.69 \\
33333333 & 6.0 & 4.9 & 0.84 \\
\hline single-flat & 15.0 & 7.5 & 0.54 \\
single-flat & 20.0 & 4.0 & 0.76 \\
\hline 3x Loc-Line & 14.0 & 6.2 & 0.81 \\
3x Loc-Line & 20.0 & 3.9 & 0.82 \\
3x Loc-Line & 30.0 & 2.7 & 0.82
\end{tabular}

\subsection{Coolant distribution in the grinding gap}

In Fig. 9-Fig. 12 four different examples are shown for the distribution of the grinding fluid in the grinding gap. In all figures is on top the position and shape of the nozzle crosssection schematically illustrated (blue tubes or box). The coolant distribution corresponds to the light intensity in the grinding gap.

\section{single-jet round nozzle $\varnothing 1.5 \mathrm{~mm}$}

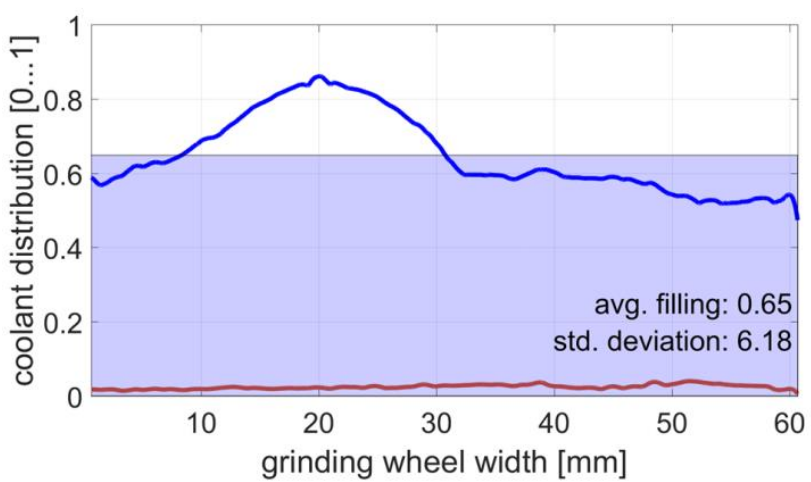

Fig. 9: Coolant distribution for single round-jet nozzle at $v_{c}=50 \mathrm{~m} / \mathrm{s}$ and $Q_{v o l}=3 \mathrm{l} / \mathrm{min}$.
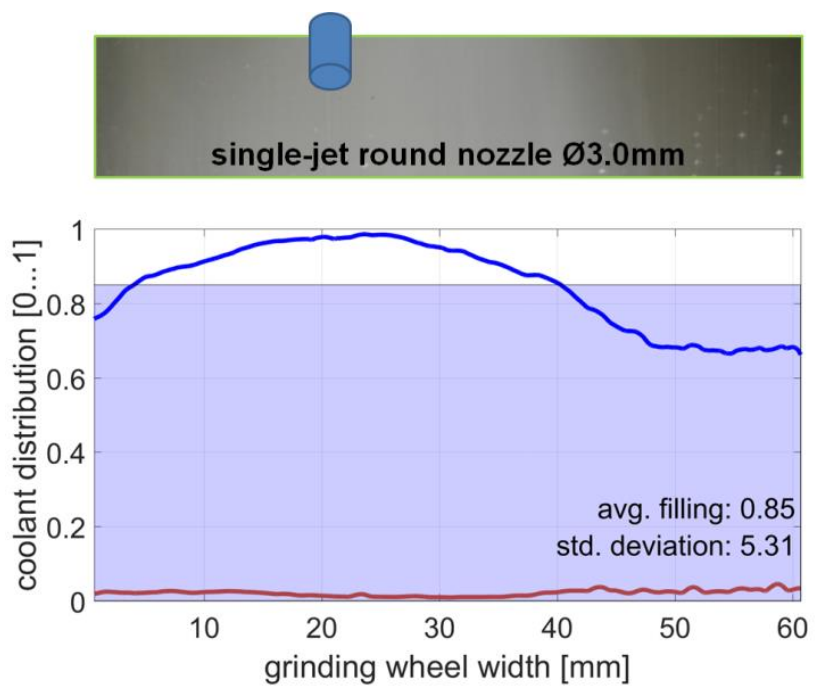

Fig. 10: Coolant distribution for a single round-jet nozzle at $v_{c}=50 \mathrm{~m} / \mathrm{s}$ and $Q_{v o l}=6 \mathrm{l} / \mathrm{min}$.
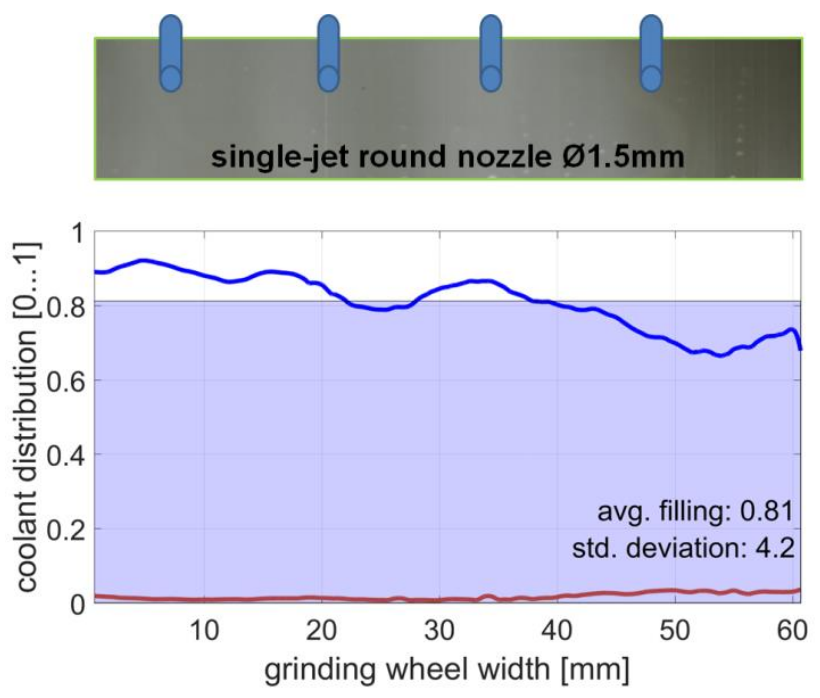

Fig. 11: Coolant distribution for 4 single round-jet nozzles at $v_{c}=50 \mathrm{~m} / \mathrm{s}$ and $Q_{v o l}=6 \mathrm{l} / \mathrm{min}$.
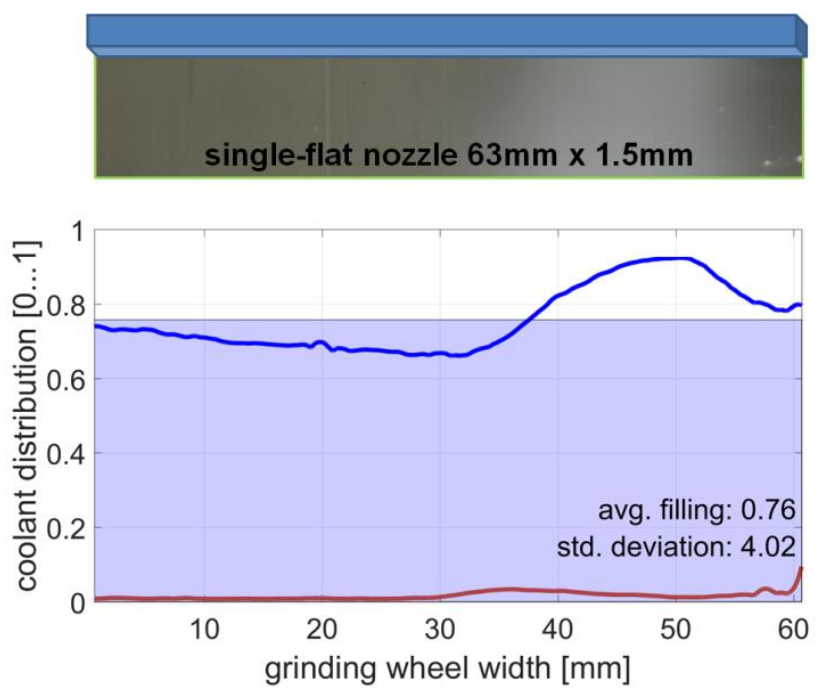

Fig. 12: Coolant distribution for a single-flat nozzle at $v_{c}=50 \mathrm{~m} / \mathrm{s}$ and $Q_{v o l}=20 \mathrm{l} / \mathrm{min}$. 
First of all none of the graphs shows a perfectly equal respectively 100 percent uniform distribution of the MWF in the grinding gap according to the proposed analysis of the images. Furthermore the influence region of one coolant jet can be distinguished clearly on the basis of the recorded images. For example in Fig. 9 a single round-jet nozzle with a diameter of $1.5 \mathrm{~mm}$ is flushing a much wider section of the grinding wheel - workpiece contact than its outlet diameter. While a doubling of the volume flow and single nozzle diameter in Fig. 10 gives an even wider flushing of the grinding gap by a single nozzle placed approximately in the middle of the grinding wheel contact zone. In comparison the same amount of coolant is distributed by four single nozzles, which improves the distribution of the coolant while a similar average fill factor is achieved (Fig 11). The peak value is still higher for the single nozzle. Finally as shown in Fig. 12 a flat nozzle supplying an amount of $20 \mathrm{l} / \mathrm{min}$ achieves a similar fill factor as $6 \mathrm{l} / \mathrm{min}$ with 4 single jet nozzles, which demonstrates the superiority of the single tube nozzles over flat nozzles.

\subsection{Grinding experiments}

The results of the residual stress measurements along the workpiece axis are shown in Fig. 13 and Fig. 14. Fig. 13 shows with the black curve positive (tensile) residual stresses of a non-ground workpiece. Below with equally distributed compressive stresses of about $-200 \mathrm{MPa}$ are shown normal cooling conditions. The used coolant nozzles are a single flat nozzle with a supply of $30 \mathrm{l} / \mathrm{min}$, 8 single round-jet nozzles of $1.5 \mathrm{~mm}$ diameter in an axial distance of $7 \mathrm{~mm}$ supplying 5.5 and $10.5 \mathrm{l} / \mathrm{min}$ of MWF. The reduced residual stresses towards the sides are assumed to be due to the workpiece geometry, as the sides are cooled also over the end surfaces.

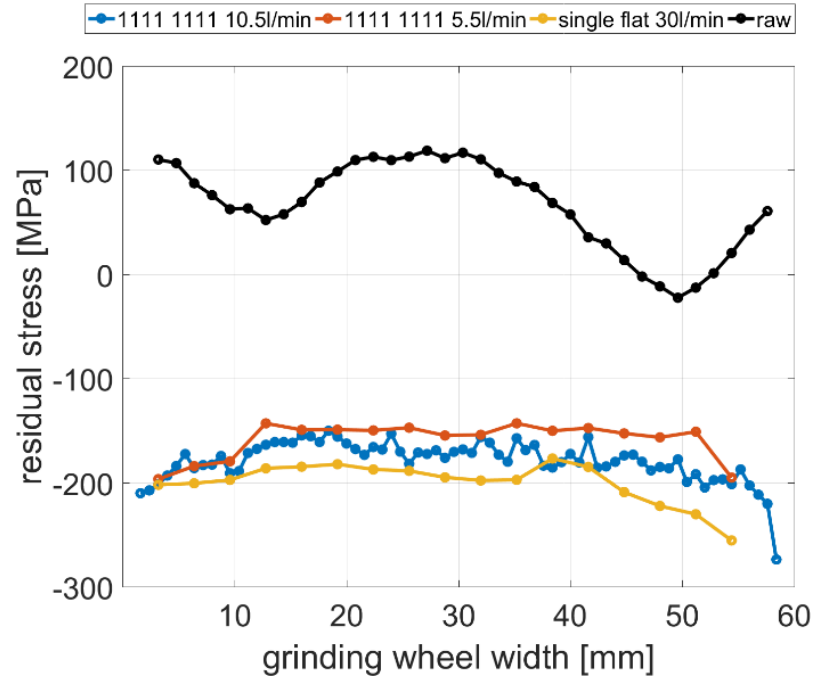

Fig. 13: Residual stress distributions in axial direction of workpiece for not ground workpiece (raw) and ground workpieces with homogeneous MWF distribution.

A complete different stress distribution due to non-equal coolant supply is visible in Fig. 14. The yellow curve of a single $\varnothing 3.0 \mathrm{~mm}$ nozzle on left side of the workpiece with a flowrate of $7.0 \mathrm{l} / \mathrm{min}$ shows two sections from left to right, where in the region of coolant supply on the left side normal compressive stresses of about $-200 \mathrm{MPa}$ can be measured, which are switching to tensile stresses at about $20 \mathrm{~mm}$ of the workpiece width going up to $+600 \mathrm{MPa}$. Even more drastic is the progression for the blue curve, which shows a single nozzle of $1.5 \mathrm{~mm}$ diameter with a volume flow of
$3.0 \mathrm{l} / \mathrm{min}$. The residual stresses do not only switch already at about $10 \mathrm{~mm}$ workpiece width to more than $+600 \mathrm{MPa}$ but also decrease back to $0 \mathrm{MPa}$ in the further progression to the right side of the workpiece. Tensile stresses are results of overheating. A visible inspection which is shown in Fig. 15 makes clear, that the workpiece suffers from severe grinding burn on the right side. It is remarked that the other workpieces show no visible signs of the measured residual stress changes. Finally the red line shows the impact of 4 single nozzles (4 single $\varnothing 1.5 \mathrm{~mm}$ nozzles at $14 \mathrm{~mm}$ axial distance with $8.0 \mathrm{l} / \mathrm{min}$ ). In this supply situation are peaks of internal stresses between the nozzles visible which stem from the too high distance of the nozzles in contrast to the red and blue line in Fig. 13, where 8 single round-jet nozzles of the same size, but with even less MWF supply achieve much better results. As shown in Fig. 15 these marks are not visible with the naked eye.

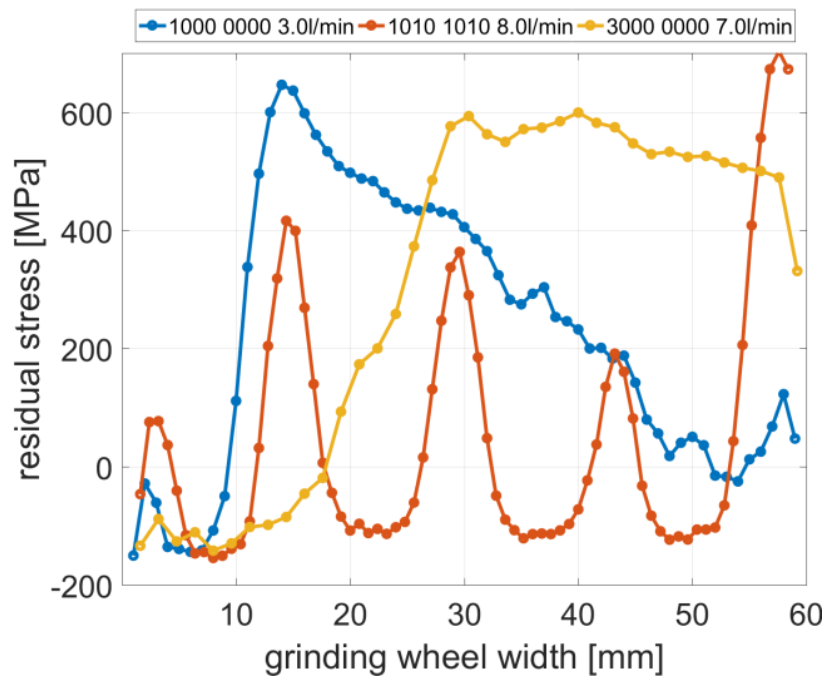

Fig. 14: Residual stress distributions in axial direction for not homogeneous MWF distribution due to the use of various single round-jet nozzle combinations.
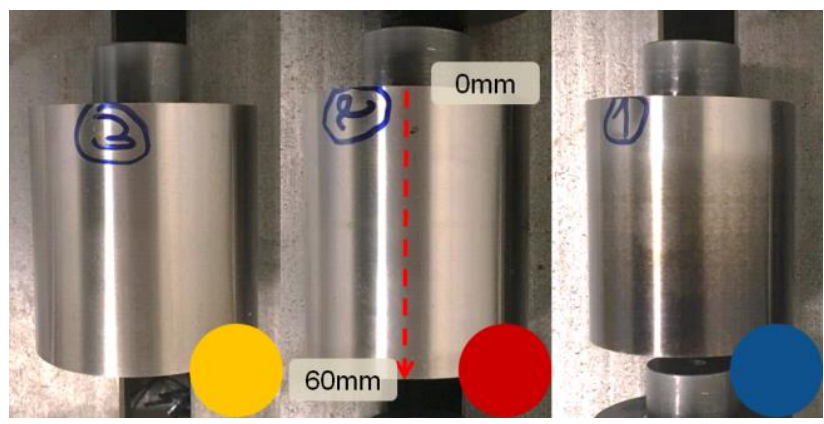

Fig. 15: Workpieces according to graphs in Fig. 14.

\section{CONCLUSION}

A new method is proposed to investigate the coolant distribution in the grinding gap for cylindrical grinding by replacing the workpiece by a lucent Plexiglas tube. Images can be taken from inside the tube pointing onto the grinding gap by a suitable mirror-camera arrangement. During the recordings the grinding wheel can be operated at full speed including the coolant supply at normal operating conditions. After image processing correcting the base illumination, differences due to different nozzle designs or coolant flow rates can be evaluated. Besides differences in the 
distribution also differences in the average mean filling of the grinding gap can be determined.

A comparison with grinding experiments shows conformity in the main predications. As visually observed a single round-jet nozzle has a much higher influence region as its original diameter of the nozzle cross-section. This effect is not primarily caused by the expansion of the fluid jet but rather due to the squeezing of the coolant in front of the grinding gap. Furthermore it is observed that apparently equal distributing coolant jets like flat nozzles not necessarily provide an equally distributed coolant distribution in the grinding gap and are much less efficient in the fluid supply than the single round nozzles. Comparing these results with the residual stress measurements two main conclusions can be drawn. First of all a minimum filling is necessary to achieve a suitable grinding result. On the other hand a high average filling does not necessarily correspond to an equal fulling of the grinding gap, which is shown by the residual stress measurements.

The judgement of small differences in the visible observed fluid distribution is still difficult. As it is observed in the grinding experiments, they can lead to large differences in the workpiece surface, as seen for wide distance single round-jet nozzles. Furthermore based on this test set-up the illumination is still difficult as the light is provided from outside of the grinding gap and outside of the machine. Further improvements include the light distribution form inside if the Plexiglas tube.

\section{ACKNOWLEDGMENTS}

The authors would like to thank Fritz Studer AG and Blaser Swisslube AG for providing machine, tools and coolants as well as Albert Weber for helping in the design and construction of the test rig.

\section{REFERENCES}

[Aurich 2014] Aurich, J. and Effgen, C. CIRP Encyclopedia of Production Engineering - Grinding. Springer, Berlin, Heidelberg, 2014, pp 586-589.

[Azarhoushang 2017] Azarhoushang, B., Daneshi, A. and Lee, D.H. Evaluation of thermal damages and residual stresses in dry grinding by structured wheels. Journal of Cleaner Production, 2017, Vol. 142, pp 1922-1930.

[Cui 1995] Cui, C. Experimental investigation of thermofluid effects in the grinding zone. Dissertation, University of Connecticut, 1995.

[da Silva 2013] Silva, L.R., Corrêa, E.C.S., Brandão, J.R. and de Ávila, R.F. Environmentally friendly manufacturing: Behavior analysis of minimum quantity of lubricant - MQL in grinding process. Journal of Cleaner Production, 2013.

[Dixit 2011] Dixit, U.S., Sarma, D.K. and Davim, J.P. Environmentally Friendly Machining, Springer, New York, 2011.

[Fritz 2018] Fritz, A.H. Fertigungstechnik. SpringerLehrbuch, 2018.

[Gviniashvili 2004] Gviniashvili, V.K., Woolley, N.H. and Rowe, W.B. Useful flowrate in grinding. International Journal of Machine Tools and Manufacture, 2004, 44:8, pp 629-636.
[Heinzel 2015] Heinzel, C., Meyer, D., Kolkwitz, B. and Eckebrecht, J. Advanced approach for a demand-oriented fluid supply in grinding. CIRP Annals, 2015, Vol. 64, pp 333-336.

[Jackson 2005] Jackson, A.R., Morgan, M.N., Batako, A.D.L. and D.R. Allanson. Fluid delivery in grinding: A review of the term:'useful flow'. In GERI Annual Research Symposium, 2005.

[Karpuschewski 1995] Karpuschewski, B. Mikromagnetische Randzonenanalyse geschliffener einsatzgehärteter Bauteile. Dissertation, Universität Hannover, 1995.

[Klocke 1996] Klocke, F. and Bücker, C. Trockenschleifen: Grenzbetrachtung zur Kühlschmierstoffreduzierung. Industriediamantenrundschau IDR, 1996, 30(1):10.

[Malkin 1974] Malkin, S. and Anderson, R.B. Thermal aspects of grinding: Part 1 - energy partition. Journal of Engineering for Industry, 1974, 96(4), pp 26-35.

[Pang 2018] Pang, J., Wu, C., Shen, Y., Liu, S., Wang, Q. and $\mathrm{Li}, \mathrm{B}$. Heat flux distribution and temperature prediction model for dry and wet cylindrical plunge grinding. Proceedings of the Institution of Mechanical Engineers, Part B: Journal of Engineering Manufacture, 2018, pp 20472060.

[Powell 1979] Powell, J. The Application of grinding Fluid in Creep Feed grinding. Dissertation, Univ. of Bristol, 1979.

[Marinescu 2013] Marinescu, I.D., Rowe, W.B., Dimitrov, B. and Ohmori, $H$. Tribology of Abrasive Machining Processes. Elsevier, William Andrew, Second Edition, 2013.

[Morgan 2008] Morgan, M.N., Jackson A.R., Wua, H., Baines-Jones, V., Batako, A. and Rowe, W.B. Optimisation of fluid application in grinding. CIRP Annals, 2008, Vol. 57, pp 363-366.

[Sreejith 2000] Sreejith, P.S. and Ngoi, B.K.A. Dry machining: Machining of the future. Journal of Materials Processing Technology, 2000, Vol 101(1), pp 287-291.

[Tawakoli 2008] Tawakoli, T., Azarhoushang, B. Dry Grinding of Soft Steel With Use of Ultrasonic Vibrations, The 6th International Conference on Manufacturing Research (ICMR08), Brunel University, 2008.

[Tönshoff 1997] Tönshoff, H.K., Karpuschewski, B. and Borbe, C. Comparison of basic mechanisms in cutting and grinding of hardened steel. Annals of the German Academic Society for Production Engineering, 1997, Vol. 4, pp 5-8.

[Tönshoff 1998] Tönshoff, H.K., Karpuschewski, B., Mandrysch, T. and Inasaki, I. Grinding process achievements and their consequences on machine tools challenges and opportunities. CIRP Annals, 1998, Vol. 47(2), pp 651-668.

[Wang 2014] Wang, C.Y., Zhang, L. and Yang, C.F. Analysis and simulation of air flow field surrounding grinding wheel. Advanced Materials Research, 2014, Vol. 1027, pp 12-15.

[Wittmann 2004] Wittmann, M., Heinzel, C. and Brinksmeier,E. Evaluating the effciency of coolant supply systems in grinding. Production Engineering, 2004, XI/2:4. 